\title{
Applying the ACPA/NASPA Competencies in the Development of a Student Affairs Graduate Professional Preparation Course in the UK
}

\author{
Roxanne DuVivier ${ }^{1}$ \\ Catherine Lee ${ }^{2}$ \\ Adrianne Johnson ${ }^{3}$
}

\begin{abstract}
This research study investigated the application of the American College Personnel Association/National Association of Student Personnel Administrators (ACPA/NASPA) competencies in the development of a graduate preparation course at a large, multi-campus research university in the UK. Expert practitioner feedback was used to adapt the competency framework and construct a tool for use in a British higher education setting. One hundred and five Student Affairs professionals participated in the resulting mixed methods study. Findings from this study have implication for applying the ACPA/NASPA professional competencies in the development of postgraduate professional preparation courses outside of the continental US.
\end{abstract}

Keywords: student affairs professional preparation, competencies in higher education

\section{Introduction}

This research study examined the use of the American College Personnel Association/National Association of Student Personnel Administrators (ACPA/NASPA) professional competencies developed and most frequently applied in the United States of America (US) to inform the development of a Student Affairs graduate professional preparation course in the United Kingdom (UK). It sought to examine the relative benefits and challenges of this international application. The researchers developed the quantitative and qualitative methods used, and applied results of these competency measures in building academic courses. The researchers applied social constructivist perspectives that suggest that learners construct knowledge out of their own experiences (Vygotsky, 1978). They sought to capture the learning associated with the process of applying higher education professional standards developed in the US to another cultural setting, a process for which there was no suggested protocol. This study was guided by the following three research questions:

1. How appropriate are the ACPA/NASPA competency categories in describing Student Affairs work in a higher education setting outside of the continental US?

2. For global use, how culturally universal or limiting is the language used in describing the ACPA/NASPA competencies?

3. What benefit, if any, is derived from evaluating prospective students' competency levels before designing professional preparation courses?

In the US, postgraduate Student Affairs courses that focus on both pre-service and in-service professional education of all those who support the student experience, are well established. Those supporting the higher education student experience in the UK, while frequently participating in postgraduate professional development, had no equivalent degree path or

\footnotetext{
${ }^{1}$ Roxanne DuVivier, Department of Leadership Studies in Education and Organisations, College of Education and Human Services, Wright State University, Dayton, Ohio, USA

${ }^{2}$ Catherine Lee, Faculty of Health, Social Care and Education. Anglia Ruskin University, Cambridge, UK

${ }^{3}$ Adrianne Johnson, Department of Human Services, College of Education and Human Services, Wright State University, Dayton, Ohio, USA
} 
award specific to Student Affairs.

UK higher education sectors have undergone unprecedented levels of change and diversification in recent years (Hazelkorn, 2015). Correspondingly, those working to support the student higher education experience have developed and expanded their roles to meet these challenges. At a time when UK universities and colleges place a higher priority than ever on the student experience and student satisfaction, higher education institutions require personnel who command a wide range of skills and knowledge, and are competent in applying their experience in a highly complex and wide-ranging professional environment. Due to both changing demographics and the introduction of a new undergraduate funding system, the UK landscape appears to be progressively aligning with trending US higher education priorities (Universities UK, 2015). There are numerous explanations for these similarities.

It is known that the UK higher education tradition is a hybrid of the historically British collegiate emphasis on the development of character, the European university emphasis on developing intellect combined with US democratic values that emphasise individualism and personal liberties (Fried \&, Lewis, 2015). Approaches originating in the US have become better known throughout the world as societal globalisation occurs. It is important, however, to recognise that though the theoretical and philosophical underpinnings of UK and US higher education are indelibly aligned, the contextual realities that exist in the US may differ somewhat or substantially from those in the UK, making full adoption of US processes ill advised.

\section{Literature review}

In the early twentieth century, the US, after a great economic depression and affected by the winds of a second world war, embraced a new sensitisation to the importance of the individual in society. This altered awareness was key to the creation of the landmark document that is considered foundational to the profession of Student Affairs, called the Student Personnel Point of View. This report, written by a group of college presidents representing the American Council on Education (ACE) defined (ACE, 1937) and later refined (ACE, 1949) the profession's philosophical foundations. The issuance of this report created a shift in US higher education priorities by expanding the university's role in developing students in a multifaceted context. It began the practice of aligning university resources to develop students emotionally, physically, socially and spiritually to augment their intellectual growth and improve their capacity for success.

Over the next few decades, many aspects of this expansion continued to evolve. By the middle part of the twentieth century, US students' rights and freedoms on campuses across the nation became integral parts of university policy that were afforded to all students (Joint Statement of Rights and Freedoms, AAUP, 1967). The university's responsibility for student development became a recognised part of its work (Brown, ACPA, 1972) and the manner in which Student Affairs contributes to the learning enterprise was defined and expanded (ACPA, 1996; Keeling, 2004, 2006).

Opportunities for engagement in value-added, out of classroom experiences steadily increased due to research that persuasively connected greater levels of student involvement with increased rates of persistence (Astin, 1984; Tinto, 1993; Kuh, 2007; Kinsey, Kuh, Schuh, Whitt, 2005; Miller, Tyree, Riegler \& Herreid, 2010). These studies provided empirical validation for the work that Student Affairs members of staff perform. Their 
findings supported the assertion that the out of classroom learning opportunities most frequently offered by Student Affairs professionals amplify the effects of academic coursework and directly contribute to both degree completion rates and to the production of more well -rounded graduates.

The profession comprises individuals with diverse undergraduate majors, interests, and backgrounds joined by a common interest in providing service and courses to college students. There is evidence to suggest that professional preparation courses strengthen professional functioning of these members of staff by instilling in this otherwise diverse group, a general professional competence that is critical to career success (Delworth, Hanson, \& Associates, 1992; Hyman, 1988; Sandeen,1982; Stamatakos,1981). In 2010, the Joint ACPA/NASPA Task Force on the Future of Student Affairs formulated an agreed-upon set of guidelines for the knowledge, skills and dispositions needed to work in the profession in ten (10) critical practice domains (ACPA/NASPA, 2010).

The task force issued a report that, among other challenges, charged the profession with designing and ensuring high quality professional development courses to ensure continuity of effective practice. It focused attention on growing international knowledge networks and enhancing channels of communication. The report further outlined the relevance of establishing global linkages to support social and economic justice, the preservation of natural resources and in support of perpetuating the fabric of democracy. The competency document was revised and re-issued in 2015 to address changes in practitioner role demands. Both the 2007 ACPA Steering Committee and two subsequent joint national Task Forces contend that the competencies represent broad skills, views and understandings and derive their relevance when they are applied in an institutional context.

\section{Methodology}

\section{Participants}

The participants in this mixed methods study were all members of staff in the Student Affairs department at one large, multi-campus UK research university. One hundred and twenty-nine members of the Student Affairs staff were invited to participate in the research study.

The gender make-up consisted of $75 \%$ females and $25 \%$ males. Ninety percent of the staff identified as members of the Caucasian culture, while $8.5 \%$ identified as Black or Minority Ethnic, and $1.5 \%$ identified as "Unknown". Nineteen percent were under age 30, 32\% were between 30 and 39 years, 20\% were between 40 and 49 years, and $29 \%$ were over 50 years.

To avoid any perception that the research had staff evaluation as a purpose, no demographic identifiers were requested. One hundred and five of the 129 members of staff agreed to participate in the study. Data collection took place during a professional development event, or Away Day, where a US competency tool adapted for use in the UK was administered and focus group research conducted.

\section{Theoretical framework}

A mixed methods approach, and way of thinking, guided the social inquiry so the researchers could assess, in multiple ways, the standpoints of participants and what was important to them and most valued by them (Greene, 2008).

The interpretive framework that guided the researchers work was that of Social Constructivism. The researchers subscribed to the ontological beliefs that "multiple realities 
are constructed through our lived experiences and interactions with others" (Creswell, 2013). The researchers were guided by their epistemological beliefs that "reality is co-constructed between the researcher and the researched and shaped by individual experiences" (Creswell, 2013).

\section{Procedure}

This study was bound with a single example of the development of a non-US graduate preparation course in Student Affairs. Methodological triangulation was achieved by using two data sources to ensure a higher degree of accuracy of results (Yin, 2014). The developer of the Master of Arts (MA) course was one of the authors of this article, and while she was involved in the gathering, analysis and use of competency data, she was not involved in the subsequent analysis of process. The second researcher was not involved in the development of the adapted competency instrument, nor data collection and quantitative data reporting, but did participate in qualitative data coding. The second researcher retrospectively examined the process and developed suggestions for future transnational applications. The third researcher analysed the survey's quantitative data.

The method used in the development of the adaptive instrument was as follows. The rating scale and structure of the US competency tools were maintained but changes were made to the language and tone of the tools to reflect the context of UK Student Affairs. To do this, US versions were shared with the leadership team of the university's Student Affairs department. In a series of face-to-face meetings, members of the leadership team and the MA Course Leader considered the language of the tools in depth. The ten ACPA/NASPA headings were retained but adapted where necessary to reflect UK Student Affairs culture and practice. For example, the section entitled 'Student Learning and Development' was replaced by 'Student Experience' as UK student attainment in learning sits more typically with academic departments and Student Experience is a more familiar term for UK Student Affairs staff. Similarly, the section on 'Law, Policy and Governance' in the US competency tool was revised to read 'Policy and the Governing Body' to better fit the context in which UK Student Affairs staff operate. Each of the competency statements was then considered line by line and, where appropriate, reworded or omitted where not deemed relevant in the UK. Once the Student Affairs leadership team and MA course leader agreed to a draft version of the UK tool, it was disseminated via email to senior representatives from the Association of Managers of Student Affairs in Higher Education (AMOSSHE). Further amendments were made to the language of the tool in light of feedback from AMOSSHE representatives. The tool was then piloted with three UK Student Affairs colleagues. Where meaning and context were unclear, pilot responders were asked to annotate the tool denoting where additional clarity was required. This feedback was then collated and further minor amendments were made to the language and tone of the tool.

The researcher presented the questionnaire to the participants, and instructions for completion were given. Questions about the process were invited and then participants were randomly split into eleven groups and taken by a group facilitator to a classroom. The group facilitators were senior leaders in the university's Student Affairs department. Forty-five minutes were allocated for the completion of the questionnaire after which the group facilitator collected the questionnaires and placed them in a sealed envelope. A further 45 minutes was allocated for a focus group discussion based on themes and topics for curriculum design, and group facilitators captured the salient points on flip chart paper.

The completed questionnaires and focus group flip chart feedback were collated by a research 
assistant. The questionnaire responses were collated individually where the skill levels and gaps were calculated for each participant and then collated. The focus group feedback was transcribed and coded by topic. Topics emerging three times or more were then extracted into a summary table.

The course leader and Student Affairs senior leadership team jointly analysed the quantitative and qualitative data. Themes that emerged from the data were agreed upon, then mapped into courses from which the curriculum was designed.

\section{Results}

\section{Survey research}

Table 1 provides an analysis of the UK relevant competencies measured by the adopted tool.

Table 1: Summary table of importance and skills

\begin{tabular}{|c|c|c|c|c|c|c|}
\hline Variable & $\underline{n}$ & $\underline{M}$ & $\underline{S D}$ & $\underline{t}$ & $\underline{d f}$ & $\underline{p}$ \\
\hline Advising and Helping & 105 & & 0.15 & 25.72 & 1 & 0.025 \\
\hline Importance & & 2.94 & & & & \\
\hline Skill & & 2.72 & & & & \\
\hline $\begin{array}{l}\text { Evaluation and Research } \\
\text { Importance }\end{array}$ & 105 & 2.66 & 0.14 & 25.60 & 1 & 0.024 \\
\hline Skill & & 2.46 & & & & \\
\hline $\begin{array}{r}\text { Equity, Div., and Inclusion } \\
\text { Importance }\end{array}$ & 105 & 2.94 & 0.31 & 12.36 & 1 & 0.051 \\
\hline Skill & & 2.50 & & & & \\
\hline $\begin{array}{c}\text { Ethical Professional Practice } \\
\text { Importance }\end{array}$ & 105 & 2.52 & 0.21 & 15.80 & 1 & $0.040 *$ \\
\hline Skill & & 2.22 & & & & \\
\hline $\begin{array}{c}\text { History, Philosophy, Values } \\
\text { Importance }\end{array}$ & 105 & 2.17 & 0.13 & 21.84 & 1 & $0.029 *$ \\
\hline Skill & & 1.98 & & & & \\
\hline $\begin{array}{r}\text { Human and Org. Resource } \\
\text { Importance }\end{array}$ & 105 & 2.07 & 0.13 & 20.78 & 1 & $0.030 *$ \\
\hline Skill & & 1.88 & & & & \\
\hline $\begin{array}{r}\text { Policy and the Gov. Body } \\
\text { Importance }\end{array}$ & 105 & 1.87 & 0.29 & 7.90 & 1 & 0.080 \\
\hline Skill & & 1.45 & & & & \\
\hline $\begin{array}{l}\text { Importance } \\
\text { Skill }\end{array}$ & 105 & $\begin{array}{l}2.07 \\
1.81\end{array}$ & 0.18 & 14.92 & 1 & $0.042 *$ \\
\hline $\begin{array}{l}\text { Personal Foundations } \\
\text { Importance }\end{array}$ & 105 & 2.55 & 0.23 & 14.45 & 1 & $0.044 *$ \\
\hline Skill & & 2.22 & & & & \\
\hline $\begin{array}{l}\text { Student Experience } \\
\text { Importance }\end{array}$ & 105 & 1.74 & 0.19 & 11.42 & 1 & 0.056 \\
\hline Skill & & 1.46 & & & & \\
\hline
\end{tabular}


A significant difference between perceived importance of a competency and acquired skill levels was found in seven of the ten areas of professional competence. Significance was not found in the categories of Equity Diversity and Inclusion, Policy and the Governing Body, and Student Experience.

However, significant differences were found between importance and skills for the following seven competencies: Advising and Helping, Evaluation and Research, Ethical Professional Practice, History, Philosophy and Values, Human and Organisational Resources, Leadership, and Personal Foundations.

\section{Focus group research}

One hundred and five subjects were divided into 11 focus groups that were conducted immediately following the completion of the competency tool. Participants were asked to discuss and record answers to the following question: "If you were designing the curriculum for the new course, what are the five most important topics you would include?"

It is relevant to note that participants had benefit of considering factors recently introduced in the competency tool. Topics that were raised a minimum of three times in the focus group feedback data were determined to have been of importance to the respondents. The topics that emerged surrounded the student experience, student engagement, advising and helping, reflection, ethical professional practice, philosophy and values, practical experience, communication and interactions, rights and responsibility - boundaries in support, organisational behaviour, leadership, contemporary politics re: HE (including comparisons with EU and international) funding (current and changes), interpreting and using collected data to influence policy making, psychology of institutions, models/theories of student affairs, the role of student affairs within the university as a whole.

Several key respondent themes emerged from analysis of the qualitative, focus group data. First, it appeared that the participants, based on their commentary, did not seem used to seeing Student Affairs as a distinct discipline. While respondents recognised that Student Affairs staff comprise a sector of the higher education community, the notion that they are part of a larger and distinct professional discipline for which unique education is required, was a new concept.

Second, a distinction exists in UK higher education circles between academic and support roles. The competency questionnaire blurred the distinctions between what is viewed as academic work with the functions of student support, leaving the respondents to view the tool as lacking relevance to the UK Student Affairs landscape.

Third, the competency tool was viewed by some as evaluative and reflective and lacking practical application. One respondent stated, "Practical experience is vital and should make up a large part of the course". Another added, "Applicable strategies - don't lose sight of practical application"; while another remarked, "Doesn't make clear how the tool is relevant to our specific roles in Student Services".

Fourth, according to respondents, performing positively in all the competency categories was seen as predominantly relevant for those aspiring to managerial roles in student affairs and not as relevant to the working practitioner. Compared to the US, there is a different consciousness of organisational hierarchy and its implication for role autonomy and position power in the UK. In the US context that is central to both the original and UK adapted 
competency documents, management and staff responsibilities are not as discretely defined. In the UK context, there is a clear distinction between management work and responsibilities held by staff. One participant described the competencies as, "More aimed at management". Another stated, "There's a vast difference between jobs and different levels of hierarchy". Another described the competencies as, "Too management focused, not grass roots", while one expressed this view, "If you aspire to management roles we agree that all areas would apply although it's difficult to apply to practitioners/teams with different roles and responsibilities".

UK institutions of higher education hire their employees into positions outlined in the university's job families guide. It is well understood that only administrators perform work classified as management. Thus, the administrative work that US Student Affairs practitioners perform is neither equivalent nor relevant for UK practice.

A fifth theme emerged surrounding the role national rankings play in UK university priorities which related to Student Affairs. The National Student Survey in the UK ranks institutions according to student satisfaction levels. This fostered a heightened awareness of the role that student affairs staff play in the ranking of their universities. Numerous respondents addressed the importance of the impact of Student Affairs work on university rankings. One respondent said, "Bring the research back to student experience". Another suggested, "Learn/develop influencing skills - benefits of research can be applied to student experience directly". Yet another expressed concern over the lack of connection to UK mandates by saying "Student experience was lacking (could be more comprehensive)".

As part of a sixth theme, participants expressed consistent interest in more clearly mapping Student Affairs competencies to UK higher education standards and regulations. They wanted to see greater connection between Student Affairs job skills, education and training and employment expectations in the UK context. They offered thoughts on how this might be achieved: one participant suggested "More UK policy and governing body references", while another stated, "Include matrix standards and Quality Assurance guidelines".

A seventh theme emerged regarding lack of specific reference to UK job titles. This observation caused participants to view the document as omitting components of student affairs departments in the UK. Based on responses it would further appear that participants identified strongly with divisional or functional units and the services they perform but did not see themselves as part of a broader profession. In the words of one respondent, there are "Vast differences between jobs and different levels of hierarchy". Another expressed concern with functional relevance by saying, "Depends on your role within student services".

An eighth theme emerged relevant to the cultural appropriateness of using US platforms, concepts and tools in the UK context. Participants frequently commented on the importance of using culturally relevant language and terminology in the competency investigation. Many participants chose to comment on language that described student affairs work. One participant described the tool as "Very American", while another described it as "Clunky/wordy". Another suggested need for revision by saying, "More tailoring?" One respondent preferred the term "Relevance' level rather than 'importance", while another broadly suggested, "Language terminology could be made more relevant ('intermediate/advance')".

With regard to the proposal of developing a UK tailored course to award a Master's degree in Student Affairs, comments made were overwhelmingly positive. One participant said a 
degree path, "Enables staff to gain professional recognition". Another described the course as a, "Stepping stone needed for staff without a degree". One respondent expressed this view, "Good idea for development. Allows education profession without teaching". Another described the proposed MA as an, "Excellent chance to undertake a research project related to job role and to the benefit of the department", while another simply stated, "Good idea!! (about time)".

Participants were surveyed to determine their interests in the MA Student Affairs in Higher Education course. Results of this quantitative inquiry showed that $14 \%$ of respondents intended to immediately enrol in a planned fall start, if offered, and an additional 35\% planned to enrol in the next or subsequent September. Only 19 respondents without an MA and not currently studying in another MA course reported that they did not wish to undertake the proposed postgraduate study at all.

\section{Application of competency measures to curriculum building}

While US curriculum resources and the US professional competency tool influenced the development of this course, the team recognised crucial differences between the US MA in Student Affairs in Higher Education courses and those of other UK MA courses. Master's degree courses in the US emphasise in-depth, pre-service professional preparation and training, as the MA or MEd (Master of Education) degree is an entry-level requirement for most Student Affairs positions. Predominantly, US colleges and universities recruit recent college graduates with relevant undergraduate experience in student support, aspiring to work in the field of Student Affairs.

In contrast, UK Masters' courses in education tend to recruit experienced education practitioners seeking professional development. UK Masters' courses are based on the philosophy that knowledge can be created in practice; that dialogue promotes learning and that personal and professional reflection is a key skill in developing practitioner improvement. The UK Quality Assurance Agency benchmarks (QAA, 2008; 2012) for Masters' degrees (level seven) suggest participants should gain: A systematic understanding of knowledge, and a critical awareness of current problems and/or new insights, much of which is at, or informed by, the forefront of their academic discipline, field of study or area of professional practice; a comprehensive understanding of techniques applicable to their own research or advanced scholarship; originality in the application of knowledge, together with a practical understanding of how established techniques of research and enquiry are used to create and interpret knowledge in the discipline; conceptual understanding that enables the student to evaluate critically current research and advanced scholarship in the subject area to evaluate methodologies and develop critiques of them and, where appropriate, propose new hypotheses.

These QAA benchmark statements influenced the course aims and learning outcomes, as did university generic learning outcomes for level seven. The course was constructed to allow participants to develop as independent, autonomous and critical researchers within a diverse and flexible teaching and learning environment to suit those employed in higher education. The course was designed to encourage participants to be fully involved in the wider postgraduate research community in education. This was considered particularly important to foster writing for publication so that UK Student Affairs practitioners develop the skills required to contribute to a body of literature that, to date is almost exclusively dominated by the USA. 
The course presented a learning experience that created, developed and refined professional knowledge and skills for Student Affairs practitioners through: models of reflective practice, the interrogation of theoretical perspectives, peer learning in communities of practice and the use of existing and emergent technologies. The MA Student Affairs in Higher Education was based around four core principles: continuing professional development, research, progression routes, and internationalisation.

Data derived from the competency tool and from the subsequent focus group activity was used to construct the design and content of the UK MA Student Affairs in Higher Education curriculum. Competencies valued by and important to participants were identified across the course content.

The full-time course began with Key Issues and Themes in Higher Education Student Affairs that relates to the History, Philosophy and Values competency. This course included a broad overview of the issues and themes relevant to all those who support the student experience in UK universities. These included but were not limited to: the nature of higher education institutions; historical and social perspectives in higher education and Student Affairs; advising and supporting students; equality, inclusion and diversity; assessment of students; funding in higher education; and career development and employability.

National and International Perspectives in Higher Education Student Affairs included international Student Affairs practices, policies and perspectives and compared these to the UK or, for international participants, those of their own home country. The course developed competencies in Advising and Helping, Equity, Diversity and Inclusion and Policy and the Governing Body. Students evaluated theoretical explanations and ideological perspectives relating to higher education including, the role of the state, social and cultural capital and educational change. The impact of these factors on the student experience was also critically evaluated in depth.

After two modules rich in theory and literature relating to Student Affairs, participants joined their peers from other areas of postgraduate education in the research methods module, Investigating Education through Research. This module related directly to the Evaluation and Research Skill interests of research participants and provided the skills required to plan and design research for their postgraduate dissertation.

The Professional Enquiry in Education module required participants to apply the theory and literature acquired in the initial two modules to reflect on their own practice in a work setting. This module related to both the Ethical Professional Practice competency and participants' interest in enhancing their personal foundations for professional practice. This module offered the opportunity for participants to undertake a three-week US-based study visit. During this placement, participants completed a research project and shared their findings with US colleagues. The final presentation was recorded and formed part of the summative assessment, alongside a reflective commentary on the study visit experience.

The course concluded with a Postgraduate Major Project in which participants were invited to choose a topic linked to Student Affairs to explore in depth through a 14,000-word dissertation. Participants worked with a supervisor with expertise in the chosen field to complete the project. This module was designed as a capstone experience where synthesis of professional learning is expected and competencies of highest priority to Student Affairs work in the UK were applied. 


\section{Discussion}

This research suggests that the ACPA/NASPA competency categories have applicability for describing Student Affairs work outside of the continental US, but also have limitations.

Using the adapted competency tool and conducting focus group research around the application of Student Affairs competencies informed the research inquiry in several ways. First it was noted that seven of the ten UK competencies showed significant differences between participant importance and current skill. This demonstrated both the value of the tool in examining participant views and skills and the gap that exists in professional training. Participant free text comments affirmed the relevance of the competencies in the UK context and pinpointed the need for customisation. Discussing the competencies raised staff understanding of the importance of possessing specific skills to serve students effectively. Asking participating staff to self-identify the skills they possess by category while considering the work-related importance of these skills was a valuable exercise that generated interest in new skill building.

It is further relevant to note that though many competencies were generalisable from the US context to that of the UK, there were also areas that were not contextually relevant along with areas that were important in UK Student Affairs work and missing from the US Student Affairs competency discussion.

Two competency categories, History, Philosophy and Values, and Law, Policy and Governance were perceived to lack cross-cultural relevance. Respondents saw the History, Philosophy and Values as a significant skill gap category but noted that it is UK, not US, history and ideals that have professional relevance. While no significant difference in importance vs skills was found, respondents free text comments suggested they had interest in learning about UK Laws, Policies and Governing Bodies. They welcomed the opportunity to gain a better understanding of UK higher education in terms of political parties, immigration and the European Union. They expressed concern over the rapidly changing nature of Student Affairs in the current UK political climate along with interest in staying abreast of the many changes that directly impact their student-facing professional practice.

It is not surprising that, given the nature of the changing landscape in UK higher education, that Policy and Governing Body was an area in which survey respondents had the least amount of confidence in their present skill levels. They expressed interest in expanding knowledge and developing skills, in accordance with the priorities of university management and governing bodies.

As the UK research university had a longstanding commitment to attracting students from Widening Participation backgrounds, it is not surprising that there was no significant difference between importance and skill on the competency tool. In both their estimation of acquired skills and through their free text comments, respondents expressed confidence in their ability to deliver quality service from an inclusive social lens. They suggested that this competency be recast to address UK standards and regulations, matrix standards and quality assurance, legal necessities under Equity, Diversity and Inclusion and the National Student Survey (NSS). They further indicated in the free text comments that the instrument did not adequately address their responsibilities towards ensuring the inclusion of disabled students. They reported interest in seeing the current descriptions of equity, diversity and inclusion competencies both expanded and enhanced. While it was affirming to see strong skills in Equity, Diversity and Inclusion competencies, and no significant difference between 
importance and skill, it raised a question as to whether the competencies, as articulated, presented adequate room for UK staff growth and development.

While participants noted a significant importance vs skills gap in Evaluation and Research, they also remarked that in the UK context, there is no tradition of research in formal professional practice in Student Affairs. While they recognised the value proposition and knew they lacked skills, they saw the emphasis on research competencies as discrepant with practitioner role demands and UK requirements for time spent on student-facing service delivery.

Lastly, an important difference in US and UK Student Affairs work was illuminated by and seen throughout these research activities. The US competency categorisation system was built for application in the US. In a US context, Student Affairs duties progress to management application. Management work, however, is distinctly different from Student Affairs work in the UK context. Job duties in the UK are highly specific by job classification and management responsibilities are outside of the student affairs remit, or work duties.

Fluidity of role demands is commonplace and expected in Student Affairs work as performed in the US. There is no distinction between staff and management in either the 2010 or 2015 versions of the articulated competencies as the distinction has little relevance in US-based work. However, the difference is clear and pronounced in the UK context, where there is no overlap of staff and administrative duties. Thus, a more dichotomised articulation of tasks and roles demands is needed for the ACPA/NASPA competencies to be seen as relevant for application in the UK cultural context.

In examining the language used in the competency document in this non-US application, the researchers found that numerous terms in the US were understood differently in the UK causing some degree of resistance to embrace the ACPA/NASPA competency document, even after adaptation.

Finally, the researchers saw benefit in evaluating prospective students' competency levels before designing graduate preparation courses. Though the MA course's structure was bound by a pre-existing Master's Level framework, the competency areas of greatest value to UK Student Affairs work guided the selection of the key themes for the MA curriculum.

\section{Limitations and strengths of the study}

A mixed methods paradigm was chosen for this research inquiry. This framework provided the researchers with quantitative and qualitative results by which to view applicability of US Student Affairs standards to UK Student Affairs work. Once applicability and limitations were demonstrated, it provided an objective and subjective framework for understanding respondent priorities. Though the researchers understood the contextual necessity of absolute elimination of identifiers, the approach removed the researcher's capacity to understand within group differences. It is relevant to note that differences in the use of language may have impacted understanding, intention and responses patterns. The mixed methods approach made the research process more involved, and, thus, more time consuming for the researchers. Having two researchers involved in this study gave objectivity to the process and reduced research bias. Including a qualitative component in the form of focus group research also reduced research bias and focus group research helped to overcome any limitations posed by the quantitative measures used. Themes that emerged from the qualitative inquiry provided the researchers with a deeper understanding of the results obtained by 
administration of the adapted tool. This was especially important as the new tool was administered in a cultural context that was different from the one for which it was originally developed. The convergence of themes that arose from this mixed methods inquiry strengthened the researchers' confidence in the study's findings.

\section{Conclusions and recommendations}

This research supports the notion that the ACPA/NASPA professional competencies have applicability outside of the continental US for development of graduate preparation courses. They help shed light on areas of greatest importance for practitioner professional development and directly impact curriculum design. When the ACPA/NASPA competencies are applied to other non-US settings, the scope of Student Affairs staff versus administrative responsibilities may need to be more concisely defined.

Since the study's conclusion, ACPA and NASPA issued a 2015 competency structure and assessment rubrics (ACPA/NASPA, 2015) and these are now available as frameworks to apply and adapt. This research suggests that professional organisations providing guidance to domestic Student Affairs practitioners may be well served to consider tailoring US frameworks for local use. Customisation may increase the relevance of applying an articulated competency structure to staff training and education. It may also serve to overcome any perceptions of paternalism or resistance to embracing a framework that wholly or partially is perceived to lack cultural relevance. Findings from this research suggest that use of language that is culturally clear matters to working professionals while the inclusion of terminology that appears foreign contributes to confusion or possibly resistance.

These research findings should foster dialogue about the nature of student affairs work around the globe and highlight the need for cultural sensitivity in both the definitions used to describe student affairs work, and the competencies needed to perform it. It is appropriate that these definitions should evolve at the national, regional, or local level, around considerations of vision, mission, and governance effecting service to students. It is hoped that this research will spark conversation in professional circles around the emergence of the student affairs profession in an expanding global higher education community, and generate ideas relative to culturally appropriate, domestically determined, student centered professional practice. 


\section{References}

American Association of University Professors. (1967). Joint statement of rights and freedoms. Retrieved from https://www.aaup.org

American Council on Education. (1937). The student personnel point of view. Washington, DC: Author. Retrieved from http://www.myacpa.org/pub/documents/1937/pdf

American Council on Education. (1949). The student personnel point of view. Washington, DC: Author. Retrieved from http://www.myacpa.org/pub/documents/1949/pdf

American College Personnel Association (ACPA). (1996). The student learning imperative: Implications for student affairs. Washington, DC: Author.

Astin, A. W. (1984). Student involvement: A developmental theory for higher education. Journal of College Student Personnel, 25(4), 297-308.

Brown, R. D. (1972). Student development in tomorrow's higher education-a return to the academy. Alexandria, VA: American College Personnel Association.

College Student Educators International and National Association of Student Personnel Administrators Student Affairs Administrators in Higher Education. (2010). ACPA/NASPA professional competency areas for student affairs practitioners. Washington, DC: Authors.

College Student Educators International and National Association of Student Personnel Administrators Student Affairs Administrators in Higher Education. (2015). ACPA/NASPA professional competency areas for student affairs practitioners. Washington, DC: Authors.

Creswell, J.W. (2013). Qualitative inquiry and research design: choosing among five approaches. Thousand Oaks, CA: Sage Publications, Ltd.

Delworth, U., Hanson, G. \& Associates. (1992). New Directions for Student Services, 1992: 81-88. Doi: $10.1002 /$ ss.37119926012

Fried, J. \& Lewis, P. (translation) (2015). The middle ages. Cambridge, MA: Harvard University Press.

Greene, J. (2008). Is mixed methods social inquiry a distinctive methodology? Journal of Mixed Methods Research, 2, 7-22.

Hazelkorn, E. (2015). Globalisation and the reputation race. In Rankings and the reshaping of higher education (pp. 1-25). Palgrave Macmillan UK.

Hyman, R. (1988). Graduate preparation for professional practice: A difference of perceptions. NASPA Journal, 26, 143-150.

Keeling, R. P. (Ed.). (2004). Learning reconsidered: A campuswide focus on the student experience. Washington, DC: American College Personnel Association \& National Association of Student Personnel Administrators.

Keeling, R. P. (Ed.). (2006). Learning reconsidered 2: Implementing a campus wide focus on the student experience. Washington, DC: American College Personnel Association, Association of College and University Housing Officers- International, Association of College Unions International, National Academic Advising Association, National Association for Campus Activities, National Association of Student Personnel Administrators, \& National Intramural Recreational Sports Association.

Kinzie, J., Kuh, G., Schuh, J., Whitt, E., \& Associates. (2005). Student success in college. San Francisco, CA: Jossey-Bass.

Kuh, G. (2007). How to help students achieve. Chronicle of Higher Education, 53(41), B12.

Miller, T., Tyree, T., Riegler, K., \& Herreid, C. (2010). Results of the use of a model that predicts individual student attrition. College and University, 85(3), 12-19. Retrieved from: ProQuest Education Journals database. (ID No. 225600895).

Quality Assurance Agency for Higher Education. (2008). Higher education credit framework for England: Guidance on academic credit arrangements in higher education in England, Northern Wales, and Ireland. Gloucester, UK: Author. Retrieved from: www.qaa.ac.uk 
Quality Assurance Agency for Higher Education. (2012). Higher education credit framework for England: guidance on academic credit arrangements in higher education in England, Northern Wales, and Ireland. Gloucester, UK: Author. Retrieved from www.qaa.ac.uk

Sandeen, A. \& Barr, M.J. (2006). Critical issues for student affairs: Challenges and opportunities. San Francisco, CA: Jossey-Bass.

Stamatakos, L. C. (1981). Student affairs progress toward professionalism: Recommendations for action. Journal of College Student Personnel, 22, 105-113, 197-207.

Tinto, V. (1993). Leaving college: Rethinking the causes and cures of student attrition. (2 ${ }^{\text {nd }}$ ed.). Chicago, IL: University of Chicago Press.

Universities UK. (2015). Patterns and Trends in UK Higher Education 2015. London, UK: Universities UK.

Vygotsky, L. S. (1978). Mind in Society. Cambridge, MA: Harvard University Press.

Yin, R. (2014). Case study research design and methods (5th ed.). Thousand Oaks, CA: Sage.

The authors may be contacted via

Roxanne.DuVivier@wright.edu 


\section{Appendix}

\section{Student Affairs Competency Tool}

This survey should be anonymous, so please don't put your name on the form. Try and answer each section as honestly as you can. In particular, don't be too modest about your skills.

1. In column A: Please rate your current skill level for each competency using the scale from 14.

2. In column B: Please rate the level to which each competency is important to your current role using the scale 1-4.

3. Complete the whole survey and then, when each section is complete, calculate your total score for each column.

4. Next, calculate your average skill score and average importance score for each section by dividing your total score by the number of questions.

5. If you get time, please enter your average skill level and average importance level for each section on the summary page at the end of the survey.

6. To get an idea of whether your current skills match those required of your role, subtract the importance level from the skill level to calculate your gap score.

$A+$ gap score may mean that your skill level exceeds that required in your role

A - gap score could help you determine future professional development activities 
Student Affairs Competency Tool

In column A: Please rate your current skill level for each competency using the scale from 1-4.

In column B: Please rate the level to which each competency is important to

your current role using the scale from 1-4.

\begin{tabular}{|c|c|c|}
\hline $\begin{array}{c}\text { A } \\
\text { Skill Level }\end{array}$ & \multirow[t]{5}{*}{ Competency } & $\begin{array}{c}\text { B } \\
\text { Importance } \\
\text { Level }\end{array}$ \\
\hline $1=$ Needs Work & & $\begin{array}{l}1=\text { Not } \\
\text { Important }\end{array}$ \\
\hline 2 = Satisfactory & & $\begin{array}{l}\text { 2= Somewhat } \\
\text { Important }\end{array}$ \\
\hline 3= Good & & $\begin{array}{l}\text { 3= Very } \\
\text { Important }\end{array}$ \\
\hline 4 = Excellent & & 4 = Essential \\
\hline \multicolumn{3}{|c|}{ Advising and Helping } \\
\hline \multicolumn{3}{|c|}{$\begin{array}{l}\text { The Advising and Helping competency area addresses the knowledge, skills, and attitudes related to } \\
\text { providing advice, support, direction, feedback and guidance to individuals and groups. }\end{array}$} \\
\hline & $\begin{array}{l}\text { 1. Exhibit active listening skills (e.g., appropriately establishing interpersonal contact, paraphrasing, } \\
\text { perception checking, summarising, questioning, encouraging, avoid interrupting, clarifying). }\end{array}$ & \\
\hline & 2. Establish a rapport with students, groups, colleagues, and others. & \\
\hline & 3. Facilitate reflection to help others make meaning from experience. & \\
\hline & 4. Pursue multiple objectives in conversations with students. & \\
\hline & 5. Facilitate problem-solving. & \\
\hline & 6. Promote individual decision-making and goal-setting. & \\
\hline & 7. Challenge and encourage students and colleagues effectively. & \\
\hline & $\begin{array}{l}\text { 8. Know and use referral sources (e.g., other offices, outside agencies, knowledge sources), and exhibit } \\
\text { referral skills in seeking expert assistance. }\end{array}$ & \\
\hline & $\begin{array}{l}\text { 9. Identify when and with whom to implement appropriate crisis management and intervention } \\
\text { responses. }\end{array}$ & \\
\hline
\end{tabular}




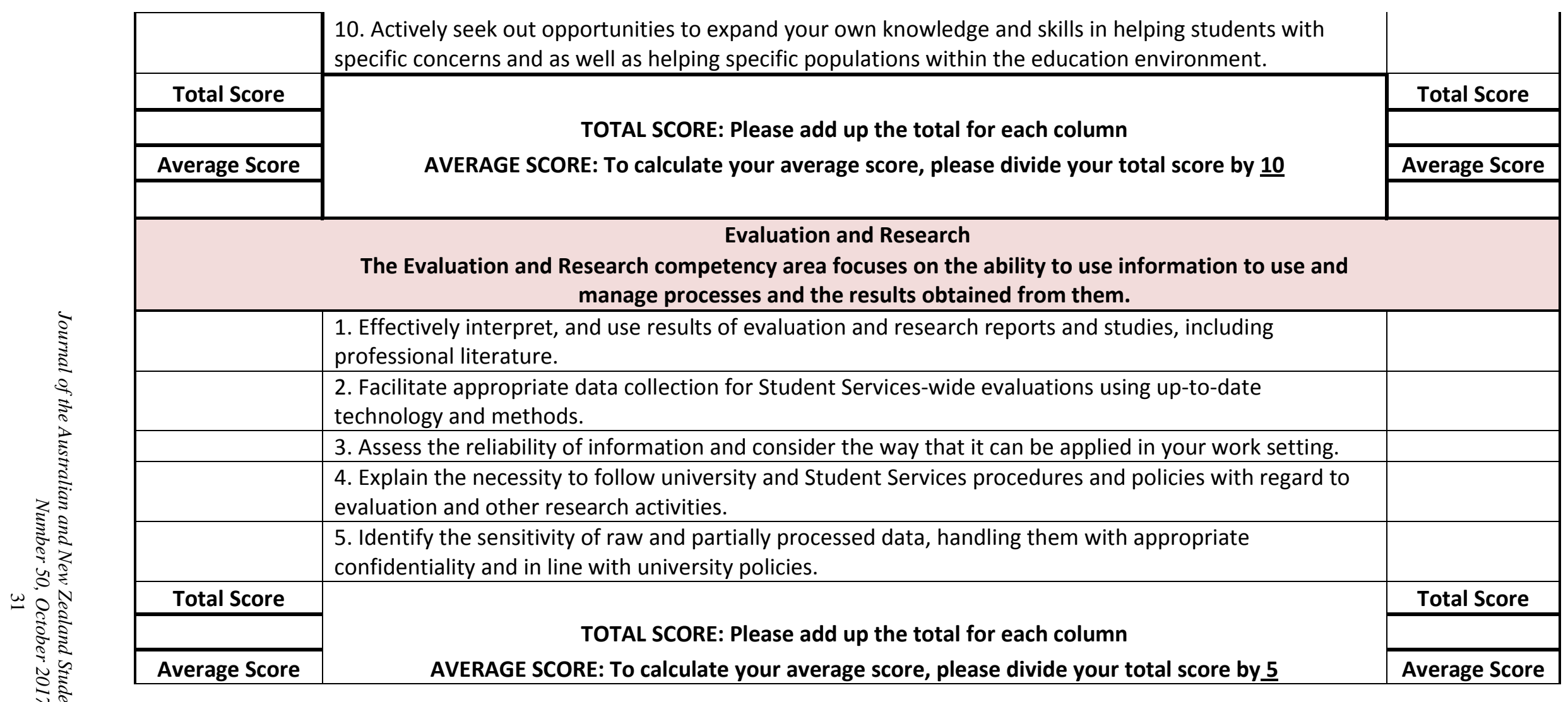


Equity, Diversity, and Inclusion

The Equity, Diversity, and Inclusion (EDI) competency area includes the knowledge, skills, and attitudes needed to create learning environments that are enriched with diverse views and people. It is also

designed to create a university ethos that accepts and celebrates differences among people.

1. Identify the contributions of diverse people within and to the university environment.

2. Apply cultural knowledge to specific and relevant issues on campus.

3. Facilitate dialogue effectively among different sorts of audiences.

4. Interact with diverse individuals, and implement activities and services that reflect an understanding and appreciation of cultural and human differences.

5. Recognise the diverse identities possessed by an individual and the ways in which they intersect.

6. Recognise social systems and their influence on people of diverse backgrounds.

7. Articulate an understanding of social justice and the role of higher education, the university, Student Services, and the individual, in furthering its goals.

8. Design culturally relevant and inclusive activities, services, policies, and practices.

9. Demonstrate fair treatment to all individuals and change aspects of the environment that do not promote fair treatment. 10. Identify the ways in which global perspectives impact on university learning.

Total Score

TOTAL SCORE: Please add up the total for each column

AVERAGE SCORE: To calculate your average score, please divide your total score by $\underline{10}$

Ethical Professional Practice

The Ethical Professional Practice competency area relates to the knowledge, skills, and attitudes needed to understand and apply ethical standards to all aspects of your professional practice.

1. Identify ethical issues in the course of your current role.

2. Describe the ethical principles of any professional associations directly relevant to your working context.

3. Explain how you apply the ethical principles of Student Services, particularly in relationships with students and colleagues, in the use of technology and sustainable practices, in professional settings and meetings, and in global relationships.

4. Assist students in ethical decision-making and make referrals to more experienced professionals when appropriate. 


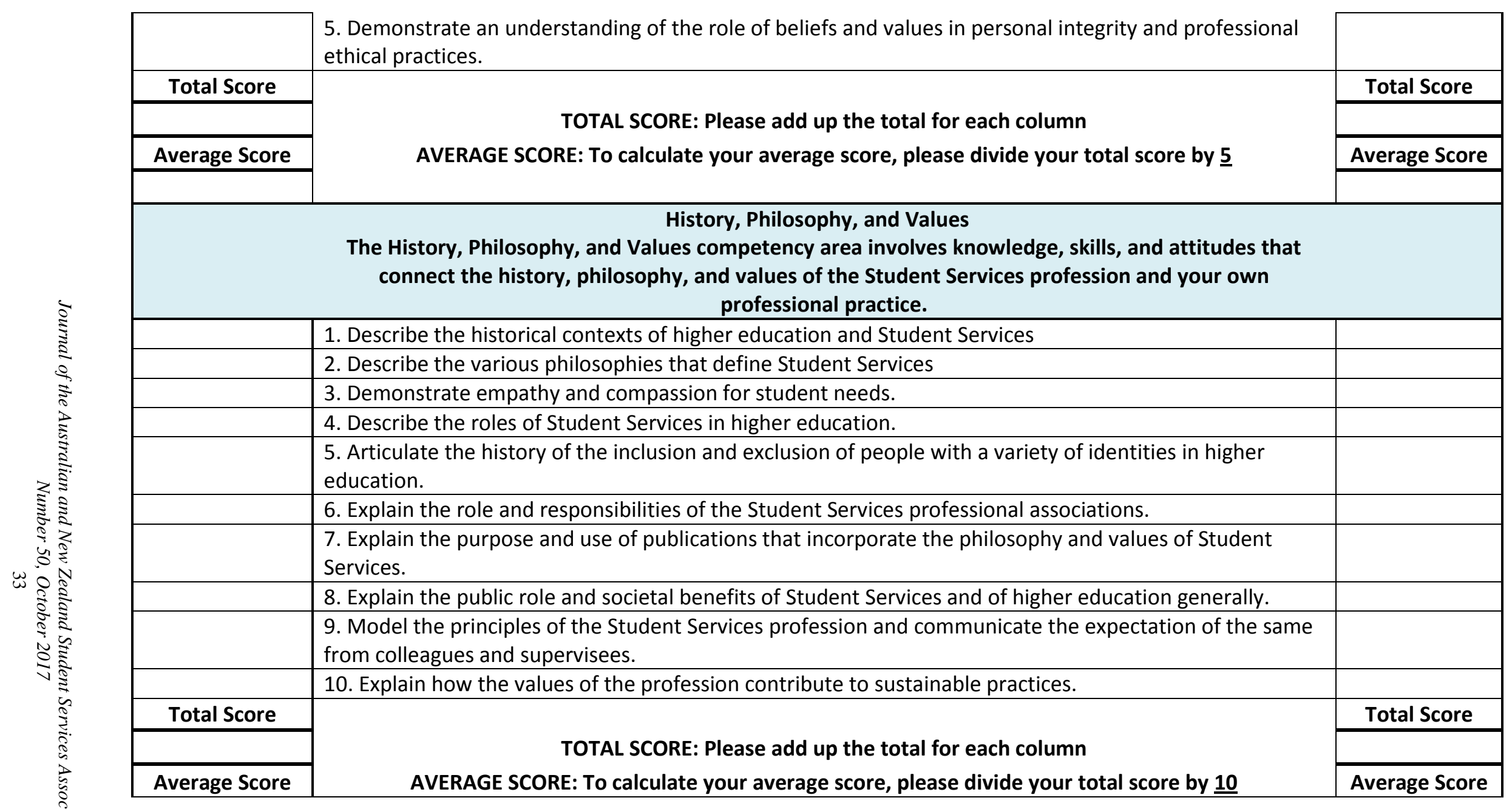




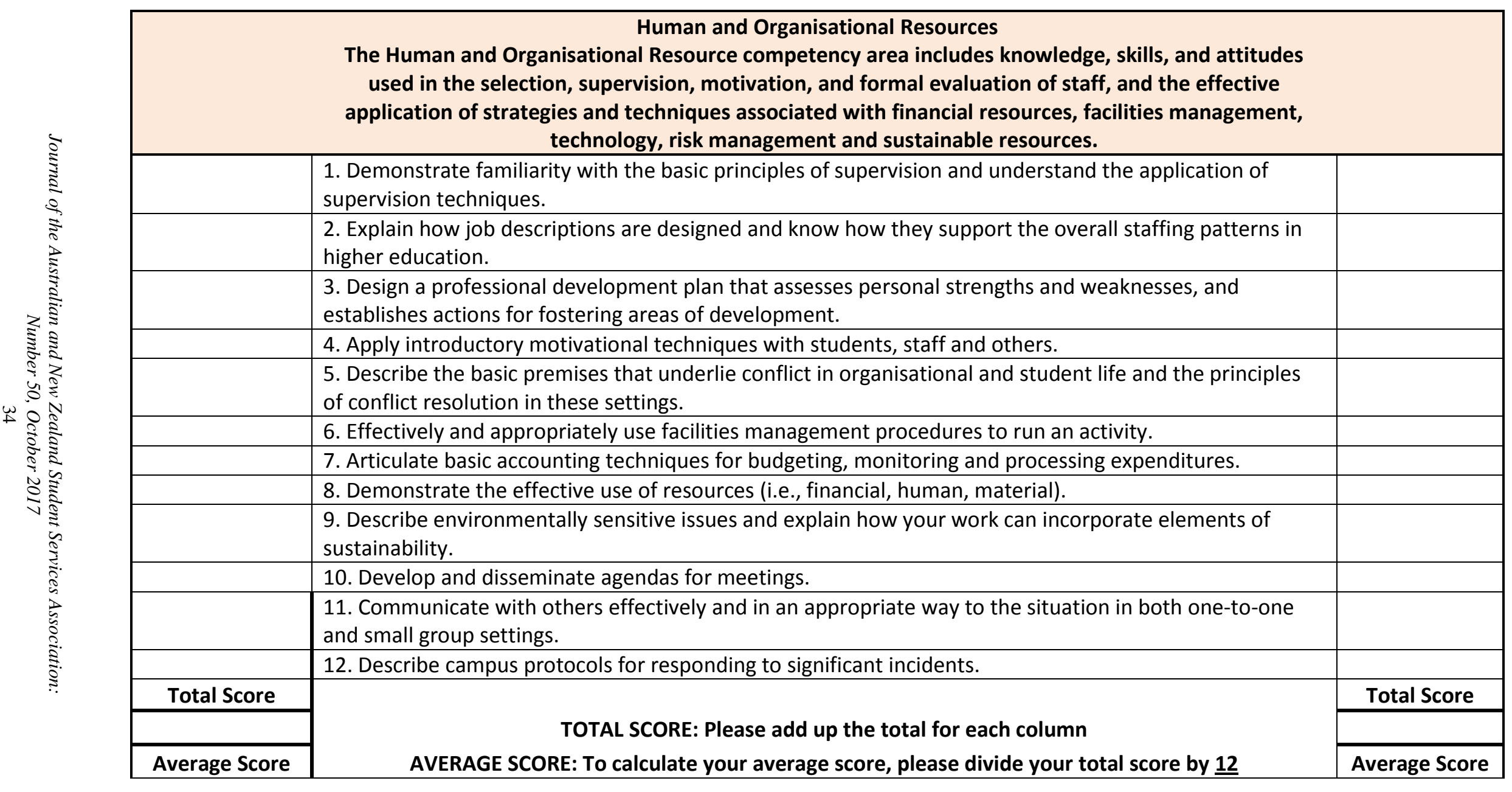




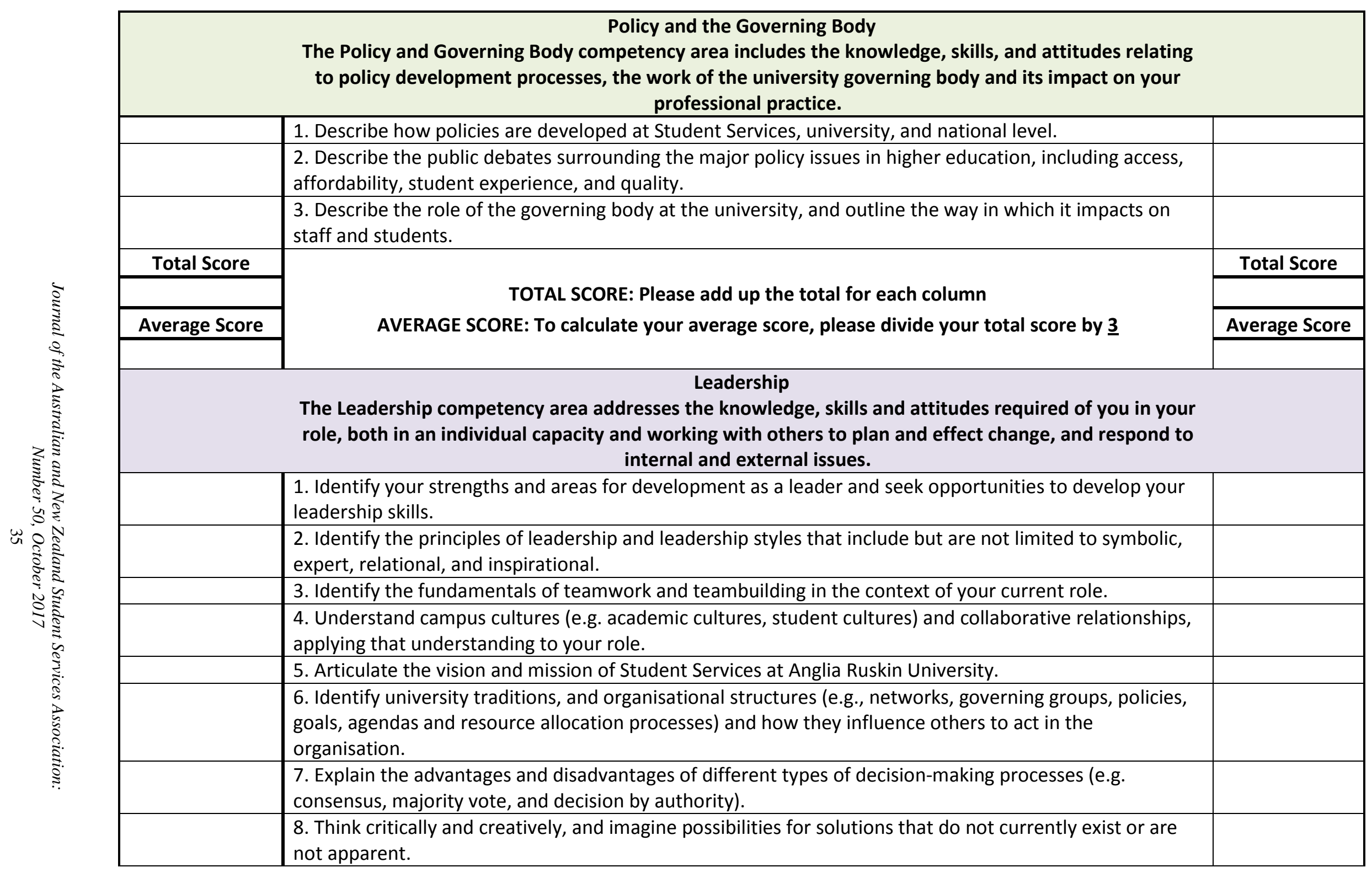


9. Identify and then effectively consult with key stakeholders to make informed decisions.

10. Explain the impact of decisions on diverse groups of people.

11. Explain and justify decision making to all interested parties.

12. Identify and introduce conversations on potential issues through appropriate channels within the

university.

Total Score

\section{TOTAL SCORE: Please add up the total for each column}

Average Score AVERAGE SCORE: To calculate your average score, please divide your total score by $\underline{12}$

\section{Personal Foundations}

The Personal Foundations competency area involves the knowledge, skills and attitudes to maintain emotional, physical, social, environmental and relational wellness; be self-directed and self-reflective; be comfortable with ambiguity; be aware of your own areas of strength and growth; have a passion for work; and remain curious.

\begin{tabular}{|c|}
\hline \\
\hline \\
\hline
\end{tabular}

1. Identify your primary work responsibilities and, with appropriate ongoing feedback, develop a realistic self-appraisal of your strengths and areas for development.

2. Describe the importance of your professional and personal life, and recognise the intersection of each. 3. Recognise and articulate healthy habits for work-life balance.

4. Articulate meaningful goals in your professional role.

5. Recognise the importance of reflection in personal and professional development.

\section{Average Score}

TOTAL SCORE: Please add up the total for each column AVERAGE SCORE: To calculate your average score, please divide your total score by $\underline{5}$ 


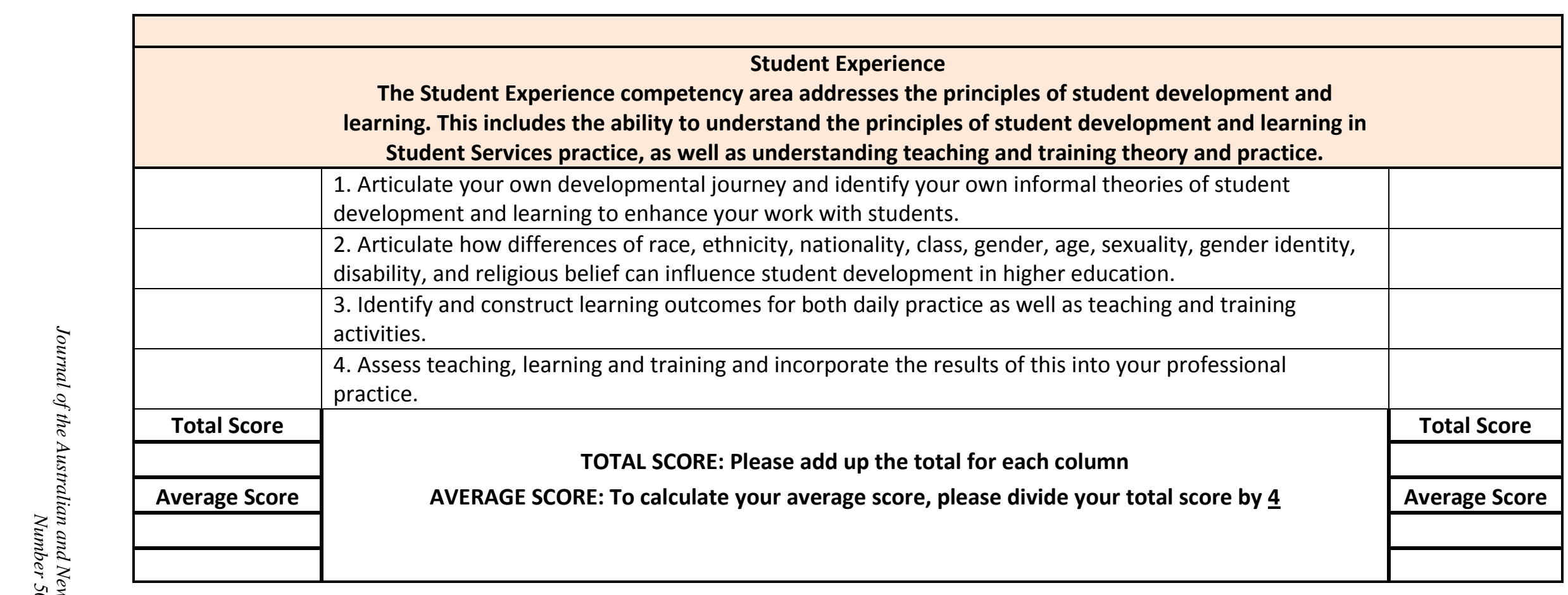




\section{Competencies Summary Page}

Using only your average scores, please enter your average skill level and average importance level for each section in the boxes below.

To get an idea of whether your current skills match those required of your role, you can subtract the importance level from the skill level to calculate your gap score.

A + Gap score may mean that your skill level exceeds that required in your role

A - Gap score could help you determine future professional development activities

Finally, in order help me understand the likely market for this course; please tick below to indicate your current position:

\begin{tabular}{|l|l|l|}
\hline \multicolumn{3}{|c|}{ Advising and Helping } \\
\hline Skill Level & Importance Level & Gap Score \\
& & \\
\hline & & \\
\hline
\end{tabular}

\begin{tabular}{|c|c|c|}
\hline \multicolumn{3}{|c|}{ Equity, Diversity and Inclusion } \\
\hline Skill Level & Importance Level & Gap Score \\
\hline & & \\
\hline
\end{tabular}

\begin{tabular}{|c|c|c|}
\hline \multicolumn{3}{|c|}{ History, Philosophy and Values } \\
\hline Skill Level & Importance Level & Gap Score \\
\hline & & \\
\hline
\end{tabular}

\begin{tabular}{|c|c|c|}
\hline \multicolumn{3}{|c|}{ Policy and the Governing Body } \\
\hline Skill Level & Importance Level & Gap Score \\
\hline & & \\
\hline
\end{tabular}

\begin{tabular}{|c|c|c|}
\hline \multicolumn{3}{|c|}{ Personal Foundations } \\
\hline Skill Level & Importance Level & Gap Score \\
\hline & & \\
\hline & & \\
\hline
\end{tabular}

\begin{tabular}{|c|c|c|}
\hline \multicolumn{3}{|c|}{ Evaluation and Research } \\
\hline Skill Level & Importance Level & Gap Score \\
\hline & & \\
\hline & & \\
\hline
\end{tabular}

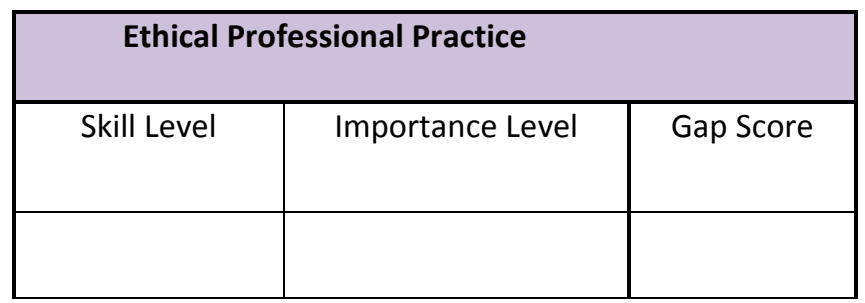

\begin{tabular}{|l|c|c|}
\hline \multicolumn{3}{|c|}{ Human and Organisational Resources } \\
\hline Skill Level & Importance Level & Gap Score \\
\hline & & \\
\hline
\end{tabular}

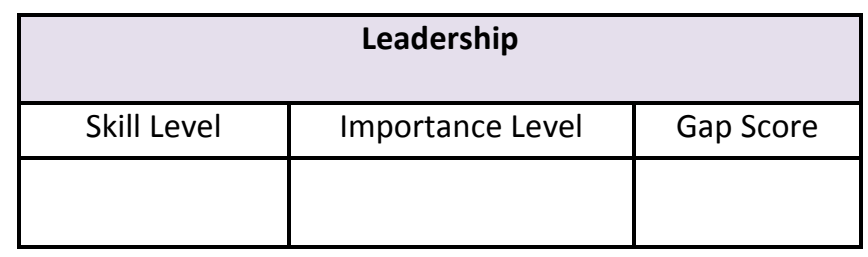

\begin{tabular}{|c|c|c|}
\hline \multicolumn{3}{|c|}{ Student Experience } \\
\hline Skill Level & Importance Level & Gap Score \\
\hline & & \\
\hline
\end{tabular}

I am interested in applying for the MA Student Affairs in Higher Education from September 2015

I am interested in applying for the MA Student Affairs in Higher Education within the next 23 years

I am currently undertaking other postgraduate study or plan to commence this in the near future

I am not interested in postgraduate study at the moment

I already have a Master's degree

Thank-you very much for your help. 